\title{
A relação entre a interação mãe-criança no desenvolvimento da linguagem oral de recém-nascidos prematuros
}

\section{Relation between mother-child interaction upon the development of oral language of the preterm newborn}

\author{
Beatriz Servilha Brocchi', Maria Isabel da Silva Leme ${ }^{2}$
}

\begin{abstract}
RESUMO
Objetivo: Verificar o impacto da interação mãe-criança no desenvolvimento da linguagem oral de crianças pré-termo, visto que a prematuridade pode prejudicar esse processo. Métodos: Participaram da pesquisa 20 díades de mães e filhos de 5 a 6 anos de idade, com diagnóstico de prematuridade ao nascimento. Realizou-se anamnese com as mães e avaliação da linguagem oral das crianças. Resultados: As mães, em sua maioria, se consideraram como as principais cuidadoras de seus filhos e referiram ser mais importante controlar o comportamento e cuidar, do que estimulá-los. As crianças, por sua vez, apresentaram desempenho abaixo do esperado para todos os testes realizados. Conclusão: Além da contribuição dos fatores biológicos associados à prematuridade, esses resultados podem ser atribuídos à quantidade e à qualidade da interação materno-infantil, visto que as mães informaram priorizar a obediência e o bom comportamento mais que o estímulo ao desenvolvimento, na educação dos filhos.
\end{abstract}

Descritores: Linguagem; Relações Mãe-Filho; Prematuro; Psicologia; Fonoaudiologia

\begin{abstract}
Purpose: To verify relations between the oral language development of preterm children and the quality of mother-child interaction. Methods: The subjects of this research were 20 mother and child dyads. An interview was conducted with the mother to obtain data about birth and life conditions. The development of oral language of the children was assessed using a test that evaluates phonology, fluency, vocabulary and pragmatics. Results: It was observed that the most part of mothers considered themselves the main caretaker and behavior's control and care are more important the stimulus in dyadic relation. All children scored bellow the expected for their age in the tests performed. Conclusion: Besides the contribution of biological factors associated to prematureness, these results can be attributed to the quantity and quality of mother-child interaction, since mothers informed to prioritize obedience and good behavior more than stimulation of the development.
\end{abstract}

Keywords: Language; Mother-child interactions; Infant, Premature; Psichology; Speech, Language and Hearing Sciences

Trabalho realizado no Instituto de Psicologia, Universidade de São Paulo - USP - São Paulo (SP), Brasil.

(1) Programa de Pós-graduação (Pós-Doutorado) em Psicologia Experimental, Instituto de Psicologia, Universidade de São Paulo - USP - São Paulo (SP), Brasil. (2) Departamento de Psicologia Escolar e do Desenvolvimento Humano, Instituto de Psicologia, Universidade de São Paulo - USP - São Paulo (SP), Brasil. Conflito de interesses: Não

Contribuição dos autores: $B S B$ pesquisador principal, elaboração da pesquisa, elaboração do cronograma, levantamento da literatura, coleta e análise dos dados, redação do artigo, submissão e trâmites do artigo; $M I S L$, orientadora, elaboração da pesquisa, elaboração do cronograma, análise dos dados, correção da redação do artigo, aprovação da versão final.

Endereço para correspondência: Beatriz Servilha Brocchi. R. Doutor Alberto Cerqueira Lima, 206/102, Taquaral, Campinas, Brasil, CEP: 13076-010.

E-mail: biaservilha@yahoo.com.br

Recebido em: 1/11/2013; Aceito em: 9/9/2013 


\section{INTRODUÇÃO}

A importância das práticas de criação para o desenvolvimento psicológico da criança, seja intelectual, seja da sociabilidade e da afetividade já foram bem estabelecidas ${ }^{(1)}$. Também estão bem estabelecidas as relações entre qualidade do vínculo afetivo da criança com a família, especialmente a mãe, e o desenvolvimento ${ }^{(2)}$. Porém, em uma revisão sistemática da literatura ${ }^{(3)}$, constatou-se que ainda são raras as investigações sobre a influência dessas práticas sobre o desenvolvimento de alguns aspectos da linguagem, importantes para a escolarização futura de bebês prematuros, em especial, quando já estão em idade escolar.

Conceitua-se recém-nascido pré-termo todo aquele que nasce antes de 37 semanas completas de idade gestacional ${ }^{(4)}$. A incidência de partos prematuros no mundo varia de 6 a $10 \%$, sendo que a maior incidência ocorre em países em desenvolvimento. No Brasil, a incidência está entre 5 e $15 \%$. As causas ainda não estão totalmente estabelecidas, porém já foram identificados alguns fatores predisponentes, como: primiparidade, condições socioeconômicas, nutrição materna, idade da mãe, intervalo entre gestações, doenças maternas, história de morte fetal anterior, mãe de baixo peso e estatura, malformações fetais, tabagismo, etc ${ }^{(4)}$.

O parto prematuro está permeado pela urgência e, por isso, pode envolver consequências negativas, tanto para a mãe quanto para o bebê, se ocorrerem restrições em função da imaturidade e instabilidade do bebê, dificultando o contato pele a pele com seus pais. A mãe, após a interrupção abrupta da gravidez, precisa lidar com muitos conflitos, como: separação imposta ao nascimento; menor responsividade do recém-nascido, em virtude da imaturidade e da precariedade de suas condições gerais; partilha do bebê com muitos profissionais e possibilidade de perda do bebê. Essa situação pode gerar na mãe sentimentos de culpa, frustração, incompetência e expectativas negativas, como ansiedade, que podem influir sobre a qualidade das interações que estabelecerá com o bebê $\hat{e}^{(5)}$. Diversos outros sentimentos podem aparecer com a situação de prematuridade do bebê, como o receio que a criança não sobreviva, adoeça com facilidade ou venha a sofrer efeitos colaterais que promovam sequelas futuras ${ }^{(6-8)}$. Assim, durante a internação, as relações se configuram de um modo particular entre o bebê, a equipe e os pais.

Os bebês pré-termo apresentam algumas peculiaridades. As crianças pré-termo, em sua maioria, apresentam, por exemplo, boa evolução neuropsicomotora, podendo, porém, evidenciar atraso nesse desenvolvimento ${ }^{(9)}$. Farão as mesmas coisas que as crianças nascidas a termo, só que mais tarde. Esse atraso vai depender das intercorrências e da estimulação do ambiente recebida pelo bebê, que podem reduzir ou aumentar os efeitos resultantes da prematuridade ${ }^{(3,5,9,10)}$.

\section{Prematuridade e desenvolvimento}

No que diz respeito à influência exercida pela interação mãe - criança prematura sobre o desenvolvimento avaliado na idade pré-escolar e escolar, foi verificada a relação entre os seguintes aspectos: responsividade materna nas interações com a criança e linguagem receptiva e expressiva da criança, condução materna adequada e habilidades sociais e cognitivas, principalmente autonomia da criança ${ }^{(3)}$.

Foi evidenciado que as mães de crianças nascidas prematuras, com desenvolvimento normal da linguagem, demonstraram mais sensibilidade às pistas emitidas pela criança, estimularam mais o seu desenvolvimento social e cognitivo, do que as mães cujas crianças apresentavam problemas de linguagem. Verificou-se, assim, que a responsividade materna nos primeiros quatro anos de vida da criança tem impacto positivo sobre a linguagem receptiva e expressiva aos 4 anos de idade ${ }^{(3)}$.

$\mathrm{O}$ desenvolvimento linguístico adequado para a idade também esteve associado à menor punição, menor restrição e disponibilização, pela mãe, de materiais apropriados para brincadeiras. É importante lembrar que os recém-nascidos pré-termo tendem a ser mais atrasados em sua organização comportamental, o que pode acarretar menor responsividade social, fator importante para o estabelecimento da relação com a mãe e com outros cuidadores ${ }^{(11)}$. É possível que, em virtude também dessa menor responsividade, o desenvolvimento da linguagem dos bebês pré-termo apresente defasagem em relação à normalidade, observando-se concomitância de comportamentos de complexidade distinta e saltos bruscos na evolução. Os fatores ambientais, como emprego (que leva a ambiente mais positivo e seguro), nível intelectual e renda familiar (quanto mais elevada, mais associada à qualidade da estimulação no lar) são considerados fatores importantes para o desenvolvimento da linguagem dos bebês pré-termo ${ }^{(3,10,12)}$.

Embora a mãe seja considerada o elemento condutor da estimulação, do ponto de vista da habilidade social para troca comunicativa, a responsividade do bebê contribui para a manutenção e complexificação da interação ${ }^{(11)}$. A pouca adaptabilidade da criança à intenção materna pode se relacionar a problemas de atenção na idade escolar ${ }^{(3)}$.

Observa-se, a partir do que foi apresentado acima, que o desenvolvimento da linguagem, em todos os seus aspectos (vocabulário, fonologia, fluência, pragmática, discursivo) está intrinsecamente relacionado às trocas sociais da criança com o meio, principalmente com a figura materna, que se apresenta como modelo e elo entre a criança e o meio em que vive. A interação entre a díade torna-se ainda mais importante no caso de crianças prematuras, que necessitam de acompanhamento e estímulo para que seu desenvolvimento seja adequado à idade cronológica, uma vez que se apresentam como grupo de risco para prejuízos em vários aspectos, dentre eles o linguístico. Verifica-se, assim, a importância da orientação da mãe para a estimulação do bebê, pois quanto mais rica e variada a interação, maior a probabilidade de efeito positivo sobre o desenvolvimento da criança.

Considerando os resultados da literatura, esta pesquisa teve 
por objetivo caracterizar o desenvolvimento da linguagem oral de crianças em idade pré-escolar, nascidas pré-termo, e verificar a influência da interação mãe-criança sobre o desenvolvimento da linguagem dessas crianças.

\section{MÉTODOS}

\section{Sujeitos}

Participaram da pesquisa 20 díades, dez meninas e dez meninos, com idade entre 5 e 6 anos (média de idade: 5 anos e 5 meses) e suas mães. Todos estiveram internados em unidade intensiva neonatal ao nascimento e foram selecionados a partir do exame de seus prontuários no Ambulatório de Alto Risco do Hospital e Maternidade Celso Pierro, onde são acompanhados desde o nascimento. A partir dos dados de identificação da mãe e da criança, foi feito o convite, pelas pesquisadoras, para participação na pesquisa.

Os critérios adotados para a inclusão foram:

1. Parto prematuro realizado no hospital em que foi desenvolvida a pesquisa;

2. Concordância da mãe em participar do trabalho e assinar o Termo de Consentimento Livre e Esclarecido;

3. Que a criança tenha recebido diagnóstico de prematuridade ao nascimento, ou seja, idade gestacional inferior a 37 semanas de idade corrigida e peso inferior a 2.000 gramas. A idade foi corrigida por meio dos testes de Capurro e New Ballard (nos casos das crianças com idade gestacional abaixo de 25 semanas).

4. Ter ficado internada em Unidade de Terapia Intensiva neonatal;

5. Ter tido acompanhamento no ambulatório de Alto Risco do mesmo hospital, desde a alta.

6. Frequentar escola do sistema regular de ensino.

Foram excluídas da pesquisa crianças com alterações no sistema nervoso central, síndromes, deficiência visual e auditiva, nascidas em outros hospitais, ou cuja mãe, no momento do convite, não tenha concordado em participar da pesquisa.

A avaliação dos pré-escolares foi realizada a partir da aprovação do projeto pelo Comitê de Ética da Pontifícia Universidade Católica de Campinas (PUCCamp) (parecer $\mathrm{n}^{\circ}$ 973/07).

\section{Material}

A fim de contemplar as questões relativas à saúde materno-infantil e à interação mãe-criança, foi elaborada uma anamnese, contendo questões abertas, com respostas preenchidas pela avaliadora. A anamnese abordou aspectos relativos aos dados de identificação, constelação familiar, histórico materno e histórico da criança, ao nascer. Especificamente sobre a interação, foram feitas perguntas sobre o sentimento materno durante a interação da criança, rotinas seguidas na vida cotidiana, disponibilidade para a criança, tipo de atividades realizadas, frequência na creche, o que era considerado prioridade na educação e as expectativas da mãe com relação à criança (Anexo 1). A anamnese foi formulada com o objetivo de contemplar todos os aspectos que envolvem a questão da prematuridade e da relação diádica desde o nascimento, como por exemplo, diretividade materna e desenvolvimento. Foi realizado um teste piloto com duas mães, a fim de adequar o roteiro para a população estudada.

A fim de avaliar todos os aspectos da linguagem infantil, foi aplicado na criança o teste fonoaudiológico denominado $\mathrm{ABFW}^{(13)}$, que tem como objetivo avaliar quatro aspectos da linguagem: fonologia, vocabulário, pragmática e fluência. Para os dois primeiros aspectos, utilizou-se um fichário de figuras do mesmo livro, que possui gravuras para nomeação de animais, alimentos, móveis e utensílios, meios de transporte, cores, formas e brinquedos. Há ainda figuras foneticamente balanceadas, que avaliam o desenvolvimento fonológico das crianças. Para os testes de pragmática e fluência foi proposta uma atividade lúdica livre com diversos brinquedos, como bola, bonecas, peças de encaixe e outros.

Para a avaliação do discurso oral, foram utilizados os seguintes materiais:

- livro chamado “Tuca, Vovó e Guto”(14), para recontagem de história;

- figura de ação para elaboração de uma história, a partir da observação da figura;

- sequência lógica de quatro figuras para a ordenação e elaboração de história, a partir do cenário observado (retirado do jogo "Sequências Lógicas" - Brinquedos Inteligentes).

\section{Procedimento}

A avaliação foi realizada em uma sala de terapia da Clínica de Fonoaudiologia da PUCCamp, de acordo com o descrito no projeto aprovado pelo Comitê de Ética da mesma instituição, em uma sessão que se dividiu em três partes: a primeira foi feita com a mãe, para a obtenção do Termo de Consentimento Livre e Esclarecido e realização da anamnese. Na segunda parte, foram avaliados os seguintes aspectos na linguagem da criança: vocabulário, fonologia e discurso. A última parte foi dedicada somente à brincadeira livre, para avaliação da fluência e da pragmática.

Todas as respostas e comportamentos dos participantes, observados pela avaliadora, foram filmados e, posteriormente transcritos nos protocolos.

\section{Análise}

As respostas obtidas na anamnese foram agrupadas de acordo com cada questão feita à mãe (Quadro 1).

Para análise dos elementos de estruturação do discurso utilizados pelas crianças, foram considerados ${ }^{(15)}$ : personagens, 
Quadro 1. Análise das respostas obtidas de acordo com cada questão feita à mãe

\begin{tabular}{|cccc|}
\hline Participantes & Renda familiar & $\begin{array}{c}\mathrm{N}^{\circ} \text { moradores } \\
\text { na casa }\end{array}$ & Estado civil \\
\hline $\mathrm{S} 1$ & $\mathrm{R} \$ 1,000,00$ & 4 & casada \\
$\mathrm{S} 2$ & $\mathrm{R} \$ 1,200,00$ & 5 & solteira \\
$\mathrm{S} 20$ & $\mathrm{R} \$ 800,00$ & 4 & casada \\
\hline
\end{tabular}

manutenção do tópico, trama/evento principal e desfecho, conforme as seguintes classificações:

1. Manutenção do personagem principal:

P1: Personagem principal indefinido, havendo vários personagens, sem que seja possível definir o principal;

P2: Personagem principal definido, mas que desaparece no decorrer da história, podendo retornar ou desaparecer novamente, ou ainda, ser substituído por outro.

P3: Personagem principal definido e mantido ao longo de toda a narração. Não é substituído até o final da história.

2. Manutenção do tema/tópico ao longo de toda a narrativa:

T1: Tópico indefinido, havendo um tópico no início, substituído por outro no decorrer da narrativa.

T2: Há um tópico no início que é substituído por outro no decorrer da narrativa, porém é retomado ao final da história. T3: Permanência do tópico ao longo da história.

3. Evento/trama principal:

E1: Observa-se esboço de um evento ou presença de vários eventos, sem que haja um principal. São sequências de episódios ou ações que não se relacionam entre si.

E2: São vários eventos, sendo difícil definir o principal, mas há alguma relação entre eles.

E3: Presença de um evento principal, trama ou situação-problema central definida, que rege toda a história e ações dos personagens.

4. Desfecho que finaliza e conclui a história:

D1: Ausência de desfecho. A história é subitamente concluída.

D2: Há presença de desfecho, porém, não apresenta relação com o evento principal.

D3: Desfecho definido e estreita relação com o evento principal.

5. Produção, Nível:

N1: P1, P2 ou P3; T1, E1, D1

N2: P1, P2 ou P3; T2; E1 ou E2; D1 ou D2

N3: P2 ou P3; T3; E2 ou E3; D2;

N4: P3; E3; T3; D3

A classificação em nível 1 caracteriza-se por histórias em que há mudança de tópicos e de eventos que se sucedem desconectadamente, o que dificulta a compreensibilidade do texto. Já o nível 2 é diferenciado do anterior pelo fato de haver tendência a manter o tópico ao longo da narrativa, porém sem relação precisa com o desenvolvimento da história. O nível 3 é caracterizado pela manutenção do tópico e do evento ao longo da narrativa, mas o que prejudica a compreensão é o fato do desfecho não ter relação com os eventos narrados. O nível 4 caracteriza-se por apresentar uma cadeia narrativa conectada e centrada em um tópico definido, com conexão entre os eventos, personagens e desfecho. Apresenta estreita relação com os eventos narrados no desenvolvimento da história.

De acordo com os autores ${ }^{(15)}$, os níveis diferenciam-se de acordo com o nível de escolaridade em que as crianças se encontram. Os níveis 1 e 2 equivalem às séries iniciais, correspondentes às idades de 6 a 7 anos.

A análise da linguagem oral foi separada em quatro partes, de acordo com as provas aplicadas. Na prova de fonologia, observou-se se a criança realizou trocas fonológicas, ou não. $\mathrm{Na}$ ocorrência de trocas fonológicas, os processos fonológicos realizados pela criança no teste foram analisados, com o objetivo de verificar se eram esperados para a sua idade. Na prova de vocabulário, foram verificadas, em cada campo semântico avaliado, as designações usuais, as não designações e os processos de substituição. Analisou-se, posteriormente, o que era esperado e o que foi obtido, conforme a idade cronológica da criança, de acordo com a seguinte classificação:

- Designações por vocábulos usuais (DVU): nomeação correta do vocábulo apresentado;

- Não designação (ND);

- Processos de substituição (PS).

A pragmática foi analisada de acordo com os atos comunicativos realizados pelo sujeito, o meio comunicativo e as funções comunicativas utilizadas:

- Atos comunicativos: começam quando a interação adulto-criança, criança-adulto ou criança-objeto é iniciada, terminando quando o foco de atenção da criança muda, ou há troca de turno.

- Meio comunicativo: os atos comunicativos são divididos em três tipos: verbais (VE) - envolvem pelo menos $75 \%$ de fonemas da língua - vocais (VO) - todas as outras emissões e gestos - (G) - envolvem movimentos de corpo e rosto.

- Funções comunicativas: Para esse teste, observa-se que, a partir dos 15 meses, há um equilíbrio entre a comunicação gestual e a soma das vocalizações e verbalizações. Além disso, o número de atos comunicativos expressos por minuto varia muito entre distintos indivíduos, em diversas situações e com diferentes interlocutores. Porém, os atos comunicativos da faixa estudada foram de aproximadamente, oito por minuto.

A última análise foi a da fluência. Verificou-se a tipologia das disfluências (comuns e gagas), velocidade de fala (fluxo de sílabas e palavras por minuto) e frequência de rupturas (porcentagem de descontinuidade de fala e de disfluências gagas). As tipologias das disfluências estão divididas em dois aspectos $^{(13)}$ (Quadro 2).

De acordo com a autora, repetições de sílabas, palavras, segmentos e frases são esperadas em crianças mais novas (geralmente duas, no máximo três repetições). Pausas de até 
Quadro 2. Tipologia das disfluências

\begin{tabular}{|ll|}
\hline Disfluências comuns & Disfluências gagas \\
\hline Hesitação & Repetição de sílabas \\
Interjeição & Repetição de sons \\
Revisão & Prolongamento \\
Palavra não terminada & Bloqueio \\
Repetição de palavras e/ou & Pausa \\
frases & \\
Repetição de segmentos & Intrusão de sons ou segmentos \\
\hline
\end{tabular}

dois segundos também são esperadas. De maneira geral, as disfluências comuns excedem as disfluências gagas. A frequência de palavras, é de, aproximadamente, 160 palavras por minuto, nos adultos, taxa um pouco menor em pré-escolares, que aproximam-se desse limite na fase escolar. Quanto à sílaba, a taxa para os adultos é de, aproximadamente, 212 sílabas por minuto e em pré-escolares, a velocidade articulatória fica em torno de 170 sílabas por minuto. Também nesse aspecto, os escolares se aproximam do resultado obtido pelos adultos, na fase escolar. Nas frequências de rupturas, a porcentagem máxima de descontinuidade de fala é de $15 \%$, sendo que as rupturas consideradas gagas não podem ultrapassar 3\%.

Os resultados de cada um dos testes foram analisados em separado, em função do esperado para a idade, verificando-se sua associação com os dados resultantes da anamnese. Para tanto, foram utilizados testes de correlação de Spearman (caso ambas as variáveis fossem contínuas) ou testes Qui-quadrado de contingência (para duas variáveis categóricas). Além disso, testes de média foram utilizados para verificar a diferença entre dois (teste t) ou mais de dois (ANOVA) grupos, em função de uma ou mais variáveis contínuas dependentes. O nível de significância adotado foi de 5\%.

\section{RESULTADOS}

Em relação aos dados de anamnese, observou-se que a idade materna esteve na faixa de 26 a 47 anos e a paterna entre 25 e 45 anos. Das mães entrevistadas, $45 \%$ (nove mães) realizaram, de forma incompleta, o ensino fundamental. Apenas $25 \%$ (cinco das mães) o completaram e $30 \%$ das mães (seis) terminaram o ensino médio.

A renda familiar variou de $\mathrm{R} \$ 450$ a $\mathrm{R} \$ 3.800,00$ reais e a média de moradores da casa era em torno de quatro pessoas.

Das participantes, $85 \%$ relataram serem casadas, $10 \%$ (duas) divorciadas e uma solteira. Mais da metade (70\%) mencionou não ter planejado a gravidez, porém, quase a totalidade delas $(93 \%)$ a recebeu bem.

Quase a totalidade das mães, também, sofreu algum tipo de intercorrência durante o período de gravidez, o que ocasionou o parto prematuro. Destas, 13 (65\%) tiveram pressão alta, das quais, sete apresentaram pré-eclampsia. Duas mães (10\%) relataram perda de líquido amniótico, duas fumaram durante toda a gestação, apenas uma (5\%) apresentou sangramento e outra, $(5 \%)$ trabalhou de forma braçal durante toda a gestação. Nenhuma das mães sabia que o parto seria prematuro.

Observou-se que a maior parte dos partos (80\%) foi por cesárea, enquanto que quatro mães (20\%) tiveram parto normal.

Com relação às crianças, a maioria nasceu com peso inferior a $1500 \mathrm{~g}$ e, mais da metade, com idade gestacional (IG) de 27 a 30 semanas, caracterizando recém-nascidos prematuros extremos e de muito baixo peso ao nascimento. Apesar da prematuridade e do baixo peso, a maior parte das crianças obteve Apgar acima de cinco no primeiro minuto e no quinto minuto. Quase metade (45\%) apresentou intercorrências, como infecções ou cirurgias, durante o período de internação, que teve média de duração de 39 dias.

Tabela 1. Idade gestacional, peso e Apgar ao nascimento

\begin{tabular}{lcc}
\hline Peso, idade gestacional e Apgar & $\mathrm{n}$ & $\%$ \\
\hline Recém-nascido até $1.500 \mathrm{~g}$ & 13 & 65 \\
Recém-nascido de 1.500 até $2.570 \mathrm{~g}$ & 7 & 35 \\
Recém-nascido de 27 a 30 semanas & 9 & 45 \\
Recém-nascido de 31 a 37 semanas & 11 & 55 \\
\hline $1^{\circ}$ minuto de vida maior que 5 & 16 & 80 \\
$1^{\circ}$ minuto de vida menor que 5 & 4 & 20 \\
$5^{\circ}$ minuto de vida maior que 5 & 19 & 95 \\
$5^{\circ}$ minuto de vida menor que 5 & 1 & 5 \\
\hline
\end{tabular}

Foi constatada correlação positiva entre o tempo de internação e os resultados do Apgar no $1^{\circ}$ minuto de vida (rho $=0,681, \mathrm{p}=0,002$ ) e no $5^{\circ}$ minuto ( $\mathrm{rho}=0,607, \mathrm{p}=0,005$ ). Houve correlação negativa entre o tempo de internação e a idade gestacional $(\mathrm{IG})(\mathrm{rho}=-0,768, \mathrm{p}=0,001)$. Isso significa que quanto menor o resultado do Apgar e IG, maior o tempo de internação da criança.

A maior parte das mães (75\%) informou ter experimentado sentimento de tristeza, medo e até desespero, durante a estadia do bebê na Unidade de Terapia Intensiva Neonatal (UTIN). As demais relataram sentir confiança durante a internação.

Mais da metade delas (60\%) informou ser a principal cuidadora da criança, enquanto $40 \%$ informou dividir o cuidado com outras pessoas, como a avó (15\%), babá (10\%), escola (10\%), ou o pai $(5 \%)$.

Dentre as mães entrevistadas que informaram serem as principais cuidadoras, verificou-se que mais da metade (60\%) dispõe de um a dois períodos para ficar com a criança. As demais informaram cuidar do filho o dia todo (20\%), ou apenas nos finais de semana e feriados (20\%).

A maior parte das mães mencionou que realiza algum tipo de atividade com a criança, como brincar (85\%), levar para passear (90\%), conversar (70\%). Apenas uma minoria (3\%) lê histórias infantis para os filhos.

Apesar de mais da metade das mães ter relatado não haver 
recebido orientações quanto ao cuidado de uma criança, a mesma proporção delas considera que seguir regras, obedecer, brincar e conversar é o mais importante na educação da mesma. Quase a metade das entrevistadas considera que o mais importante na educação é o incentivo à obediência ou seguir regras. As demais, atribuem maior importância à adequação do desenvolvimento à idade. Os resultados indicaram que, para mais da metade das entrevistadas, o "saber se comportar" é o aspecto fundamental a ser alcançado na educação da criança.

Tabela 2. O que as mães consideram de mais importante na interação com a criança

\begin{tabular}{lcc}
\hline O mais importante na educação da criança & $\mathrm{n}$ & $\%$ \\
\hline Seguir regras & 2 & 10 \\
Ser obediente & 6 & 30 \\
Brincar, conversar & 0 & 0 \\
Seguir regras, ser obediente, brincar e conversar & 12 & 60 \\
\hline Saber se comportar & 12 & 60 \\
Bem desenvolvido para a idade & 2 & 10 \\
Se comportar e ser bem desenvolvido & 6 & 30 \\
\hline Quando faz algo errado conversa & 10 & 50 \\
Quando faz algo errado castiga & 4 & 20 \\
Quando faz algo errado conversa e castiga & 6 & 30 \\
\hline
\end{tabular}

\section{Desempenho das crianças na avaliação do discurso oral}

Constatou-se que, quase metade dos participantes, formulou uma história a partir da figura de ação (um bebê pegando uma bola). Na prova de sequência lógica (que consiste em ordenar temporalmente três figuras colocadas desordenadamente à frente da criança, a fim de compor uma história), todas sequenciaram de forma incorreta as figuras e metade compôs a história, mesmo com as figuras desordenadas. Apenas seis crianças fizeram a recontagem da história "Tuca, Vovó e Guto".

Tabela 3. Produção oral realizada pela criança

\begin{tabular}{lcc}
\hline Produção oral & $\mathrm{n}$ & $\%$ \\
\hline Realizou a partir de uma figura de ação & 8 & 40 \\
Não realizou a partir de uma figura de ação & 12 & 60 \\
\hline Realizou a partir de uma sequência lógica & 10 & 50 \\
Não realizou a partir de uma sequência lógica & 10 & 50 \\
\hline Realizou corretamente a sequência & 0 & 0 \\
Não realizou corretamente a sequência & 20 & 100 \\
\hline Recontou a história & 6 & 30 \\
\hline
\end{tabular}

Quando comparado o tempo de interação da mãe com a criança e o discurso oral da segunda, observaram-se diferenças entre as provas realizadas. Na prova de recontagem, o valor de $\mathrm{r}_{\mathrm{s}}=0,16$ é significativo ao nível de $\mathrm{p}<0,05$, o que indica que, quanto maior o tempo da mãe com a criança, melhor o seu desempenho na recontagem de histórias. Diferentemente da recontagem, as provas de figura de ação e sequência lógica apresentaram valores significativos, porém com correlações negativas (a comparação entre tempo de interação e figura de ação - $r_{s}=-0,15$ e $r_{s}=-0,13$ - entre tempo de interação e sucesso na realização da sequência lógica), o que significa que o tempo de interação da criança com a mãe não determina o desempenho dos participantes na produção a partir de uma figura de ação e sequência lógica.

Observou-se, a partir dos dados descritos acima que, aproximadamente metade das crianças, realizou a produção oral a partir das provas solicitadas e que o tempo de interação exerceu influência no desempenho. Dessa forma, quanto maior o tempo da mãe com a criança, melhor o desempenho da criança nas provas propostas para avaliar o discurso.

\section{Desempenho das crianças na prova de fonologia}

O desempenho dos participantes nessa prova evidenciou que, mais da metade deles (60\%), não apresentou trocas de fonemas na fala. Os demais (40\%), apresentaram algum tipo de troca esperada para a idade, como simplificação de encontro consonantal (prato-pato), ou não esperada para a idade e/ou desenvolvimento, como redução de sílabas (elefante-efante).

Por outro lado, verificou-se relação significativa entre idade gestacional $(\mathrm{t}=2,340, \mathrm{p}=0,032)$ e trocas de fonemas pela criança, ou seja, crianças nascidas com maior idade gestacional média (média=33 semanas) não apresentam trocas, como as nascidas com cerca de 30 semanas. Ao comparar o desempenho em fonologia e o tempo de interação da mãe com a criança, observou-se correlação de $r_{s}=0,16$, positiva, ao nível de $p<0,05$. Dessa forma, mais da metade das crianças do estudo apresentaram desenvolvimento fonológico normal, não apresentando trocas não esperadas para a idade, resultado atribuído a fatores como idade gestacional e tempo de interação, que quanto maiores, mais favorecem o desenvolvimento da fala da criança.

\section{Desempenho das crianças na prova de vocabulário}

Nenhum participante obteve o resultado esperado para a idade em alguns aspectos da prova de vocabulário, como designações usuais, não designação ou processos de substituição.

A comparação entre os resultados de vocabulário, tempo que a mãe disponibiliza para as crianças e atividades realizadas com elas, demonstrou associações positivas, ou seja, quanto maior o tempo que a mãe dispõe para o filho, melhor o vocabulário da criança.

Quando comparado o vocabulário com o discurso oral das crianças, observou-se associações positivas, ao nível de $\mathrm{p}<0,05$. Na prova de recontagem, a correlação também foi positiva $\left(r_{s}=0,00094\right)$. Nas outras duas provas, figura de ação 
e sequência lógica, a correlação foi negativa (figura de ação: $r_{s}=-0,249$ e sequência lógica: $r_{s}=-0,42$ ). Sendo assim, quanto maior o vocabulário, melhor o desempenho dos participantes na prova de recontagem. Porém, o tamanho de vocabulário não foi suficiente para garantir o desempenho nas provas de figura de ação e sequência lógica.

\section{Desempenho das crianças na prova de pragmática}

No teste de pragmática, foram avaliados os atos comunicativos totais (ACT) (somatória de atos comunicativos da criança e da avaliadora), os atos comunicativos realizados somente pela criança - ACC, e quantos atos comunicativos foram realizados por minuto - AC min.

Foi verificada a média de 164,3 atos comunicativos totais durante a interação criança/avaliadora, sendo que a média dos atos realizados somente pelas crianças foi de 71,3. Um quarto dos participantes (25\%), realizou metade ou mais da metade dos atos comunicativos totais e a maioria (75\%), abaixo desse índice. A partir dos índices apresentados, obteve-se a média de 3,3 atos comunicativos por minuto, realizados pelas crianças. De acordo com a autora do teste, esse índice está muito abaixo do esperado para a idade cronológica das crianças avaliadas, que seria oito atos por minuto. $\mathrm{O}$ índice apresentado equivale ao desempenho de crianças de três anos de idade ${ }^{(13)}$.

\section{Desempenho das crianças na prova de fluência}

No que diz respeito à fluência, observou-se que houve predominância das disfluências comuns (interjeição, repetição de palavras) sobre as disfluências gagas (repetição de sílabas, repetição de sons). A média do primeiro tipo foi de 6,8 , enquanto que a média de disfluências gagas foi de 0,35 . A média da proporção de descontinuidade de fala (DF) foi de $3,57 \%$ e de disfluências gagas (DG), de $0,125 \%$. A proporção de descontinuidade de fala não pode ultrapassar $15 \%$, enquanto que a de disfluências gagas não pode ultrapassar 3\%(13). De acordo com os resultados descritos, constatou-se que todas as crianças obtiveram desempenho esperado para a idade e para o desenvolvimento da fala.

Em relação à velocidade de fala (frequência de palavras por minuto e frequência de sílabas por minuto), verificou-se a média de 17,55 palavras por minuto, enquanto que a frequência de sílabas por minuto foi 28,96, em média. O desempenho do grupo de participantes em relação a esse aspecto ficou abaixo do esperado para a idade, pois a média de sílabas por minuto esperada para pré-escolares é de, aproximadamente, 170, muito superior ao realizado pelas crianças avaliadas. Observou-se correlação positiva entre o tempo de interação e velocidade da fala de $r_{s}=-0,096$, para $p<0,05$, verificando-se que, quanto maior o tempo que a mãe despende com a criança, maior a fluência da fala.

Foi possível constatar, também, a associação entre a fluência e a pragmática, uma vez que $\mathrm{r}_{\mathrm{s}}=0,648$ é significativo, ao nível de $\mathrm{p}>0,01$, o que indica que quanto maior o espaço comunicativo ocupado pela criança em uma situação interacional e quanto mais recursos comunicativos ela utiliza, maior será a fluência da fala. A mesma associação pôde ser verificada na comparação com a prova de vocabulário, em que $\mathrm{r}_{\mathrm{s}}=0,045$ foi significativo ao nível de $\mathrm{p}<0,05$, constatando-se que quanto maior o vocabulário, maior será a fluência da fala. Conclui-se, a partir desses dados que, quanto maior o vocabulário e pragmática, maior é a fluência da fala da criança. Nesses três aspectos estudados, observou-se influência efetiva da mãe, uma vez que, quanto maior o tempo dedicado à criança, melhor é o seu desempenho no desenvolvimento lexical, discursivo e, consequentemente, melhor será a fluência durante a interação.

\section{DISCUSSÃO}

Os resultados que dizem respeito aos sentimentos negativos experimentados pelas mães durante a permanência do filho na UTI neonatal, como medo da perda, desespero, sofrimento e ansiedade, concordam com os achados de diversos autores ${ }^{(7,16,17)}$ que, ao focalizar o parto prematuro, permeado pela urgência, salientam que a família, principalmente a mãe, torna-se espectadora da situação, impossibilitando o contato pele a pele desde os primeiros momentos de vida da criança apenas observando todos os procedimentos realizados em seu filho, por profissionais, sem poder fazer algo por ele, diretamente. Porém, os pais das crianças deste estudo conseguiram superar esses sentimentos, a partir do contato com a criança e a melhora de suas condições, criando, mesmo que de forma mais tardia, um vínculo com o bebê. Esse vínculo influenciará, de forma efetiva, no desenvolvimento comunicativo-linguístico da criança e o seu rompimento, logo nos primeiros minutos de vida, pode trazer consequências para o processo de desenvolvimento futuro.

As crianças, em sua maioria, apresentaram baixo peso ao nascer e quase metade delas foi prematura extrema, com tempo de internação variando entre oito e 80 dias. Em virtude das intercorrências apresentadas ao nascimento, são consideradas estas crianças são consideradas de risco, com maiores probabilidades de alterações no desenvolvimento ${ }^{(3)}$. Esses riscos, somados a outros sociais e ambientais, poderão potencializar os efeitos dessas alterações ${ }^{(16)}$.

Esse fato foi comprovado por meio dos testes realizados, em que todas as crianças ficaram abaixo do esperado para a idade, exceto na prova de verificação do discurso oral. $\mathrm{Na}$ prova de fonologia, quase a metade dos sujeitos da pesquisa apresentou desvios fonológicos, sendo a maioria desses desvios não mais esperados para o desenvolvimento. O desvio fonológico, caracterizado por fala espontânea ininteligível em idade superior a quatro anos, pode ocorrer por causas variadas, englobando questões biológicas, psicossociais, ambientais e hereditárias ${ }^{(18,19)}$. Em concordância com as autoras acima, os fatores biológicos (prematuridade e baixo peso) influenciaram 
de maneira efetiva o desempenho fonológico das crianças, uma vez que a maior parte das que apresentaram trocas foram diagnosticadas como prematuras extremas e com muito baixo peso ao nascimento. Além disso, os dados encontrados sugerem que a interação da díade mãe-bebê também foi um fator importante, haja vista a significativa correlação entre ambos (fatores biológicos e interação mãe-criança).

Dos dados coletados nas entrevistas, observou-se que, apesar de as mães considerarem que o mais importante para as crianças é brincar e conversar - e que fazem isso com seus filhos, independente da quantidade de tempo que fiquem com eles, priorizaram o comportamento. Segundo elas, o comportamento adequado favorece melhor convívio na escola, com a família e com os amigos. A brincadeira mãe-criança, relatada por diversos autores ${ }^{(20,21)}$ é um importante estimulador dos fatores do desenvolvimento sociocognitivo e linguístico da criança, uma vez que a mãe oferece segurança emocional para que a criança explore e represente, de forma independente, o ambiente, além de oferecer segurança emocional e transmitir informações para a criança, na resolução de problemas ${ }^{(22)}$.

Esse dado tem ligação direta com todas as provas realizadas com as crianças, neste trabalho. Quanto ao desenvolvimento do discurso oral, a maior parte dos participantes não realizou todas as composições orais propostas, ou por não aceitar a atividade (no momento da avaliação, a criança ficou envergonhada ou não quis realizar a atividade), ou por ter apenas descrito o que viu, ou ouviu, sem caracterizar uma história.

Embora autores relatem ${ }^{(15)}$, em seu estudo, que os níveis 1 e 2 correspondem às crianças de 6 a 7 anos (faixa etária correspondente à do estudo), apenas quatro participantes apresentaram nível dois em uma das composições realizadas. Duas delas, têm como principais cuidadoras as próprias mães e as outras duas, as avós, que brincam com elas e as incentivam à leitura, principalmente de fábulas, o que se tornou, assim, uma de suas atividades preferidas. Além disso, constatou-se associação direta entre o discurso oral e o tempo de interação e nível socioeconômico das mães do estudo. Na análise realizada, observou-se que, quanto maior o tempo da mãe com a criança e o nível socioeconômico da família, melhor o desempenho da criança nas provas propostas do discurso.

Os achados de alguns autores ${ }^{(23)}$ justificam as constatações deste estudo com relação à prova de vocabulário, em que nenhum participante apresentou o desempenho esperado para a idade cronológica, demonstrando a importância da leitura no desenvolvimento do vocabulário e, consequentemente, da linguagem, uma vez que o momento da leitura é uma ocasião potencialmente rica para o seu desenvolvimento. Além das histórias conterem pistas contextuais que ajudam a decifrar o sentido de palavras desconhecidas, também cumprem função sociocultural, isto é, ajudam as crianças a ordenar experiências vividas e estimulam a criatividade por meio da criação de histórias imaginárias. Com esses relatos, entende-se a associação positiva entre o vocabulário e o discurso oral apresentado nos dados do presente trabalho, uma vez que, quanto maior o vocabulário, melhor é o discurso da criança. Na interação verbal adulto-criança, a mãe é um modelo para o desenvolvimento verbal infantil e adapta as suas verbalizações de acordo com a capacidade verbal do filho ${ }^{(24)}$. A competência sintática depende do grau de estimulação ambiental e da apresentação de atividades que desenvolvam a capacidade de organização gramatical. A participação dos adultos nas atividades de crianças de até seis anos promove interação social, convergindo para um desenvolvimento linguístico satisfatório, o que pode ser comprovado na associação encontrada entre a escolaridade materna e o vocabulário da criança, ou seja, quanto maior a primeira, maior também o vocabulário da criança ${ }^{(25)}$.

A aquisição e o desenvolvimento lexical também são fortemente influenciados pelo processo interacional, pois a linguagem ocorre no contexto em que se está exposto. Os aspectos sociopragmáticos e as habilidades cognitivas são fundamentais para o desenvolvimento lexical da criança ${ }^{(24)}$. Esses aspectos também influenciaram o desempenho verificado na prova de pragmática, em que todas as crianças apresentaram desempenho muito abaixo do esperado para a idade.

A quantidade de atos comunicativos aquém do esperado para a idade influenciou na prova de fluência, em que os sujeitos apresentaram o fluxo de palavras por minuto e sílabas por minuto também abaixo do esperado para idade. As crianças falam mais lentamente que os adultos, o que é superado a partir da adolescência ${ }^{(26)}$. Isto se deve à imaturidade do sistema neuromotor, que está associado à produção da fala e ao desenvolvimento cognitivo ${ }^{(26)}$. Porém, as disfluências apresentadas foram, em sua maioria, do tipo disfluências comuns; as disfluências gagas também foram dentro do esperado para o falante fluente, não tendo sido encontrados casos de gagueira entre os participantes da pesquisa. Os participantes deste estudo apresentaram-se como falantes fluentes, com poucos períodos de disfluência, caracterizados, principalmente, por hesitações, interjeições e repetições de palavras e frases ${ }^{(26,27)}$.

A constatação da influência do vocabulário e da pragmática no desempenho da prova de fluência, com a correlação positiva entre os testes, significa dizer que a fluência será melhor, quanto maior o vocabulário da criança e quanto mais atos comunicativos ela produzir. Quanto maior o vocabulário, maior a fala e, portanto, a fluência. Como as crianças do estudo apresentaram um desempenho aquém do esperado nessas duas provas, o desempenho da fluência da fala também ficou prejudicado.

Os achados desta pesquisa concordam com autores ${ }^{(16,28)}$ que identificaram atraso no desenvolvimento linguístico da criança prematura, em relação à criança a termo, principalmente no que se refere à linguagem expressiva. Além dos fatores biológicos resultantes da prematuridade, os ambientais associados a esse aspecto têm grande importância, podendo contribuir para a superação ou manutenção das dificuldades resultantes.

Sabendo disso, sugere-se que, já na gravidez, as mães recebam orientações de uma equipe multiprofissional, quanto 
ao desenvolvimento esperado de uma criança e estimulações possíveis de serem realizadas durante a internação, a fim de aumentar o vínculo materno e os sentimentos positivos com relação à criança. Esses mesmos profissionais também podem sugerir atividades para serem feitas em casa, com o objetivo de propiciar o desenvolvimento do prematuro. É fundamental salientar a importância da mãe junto à criança nesse processo, em que ela aparece como modelo linguístico e comportamental para a criança e, com sua estimulação, poder atenuar possíveis consequências da prematuridade.

Os hábitos da brincadeira e da leitura são aspectos a serem reforçados, uma vez que podem influenciar, de forma positiva, no desenvolvimento de todos os aspectos linguísticos avaliados (vocabulário, pragmática, fonologia, fluência e discurso) e no fortalecimento da ligação diádica. O incentivo para a leitura, tanto de pais, quanto da escola, é essencial na formulação de um discurso coerente, com estruturas sintáticas e vocabulário adequado, o que acarretará, futuramente, em melhor aprendizado da leitura e da escrita

As regras de comportamento e a obediência são importantes na educação da criança, mas não podem ser a prioridade. A mãe, como provedora de conhecimento e base segura para criança, durante as atividades, permite a ela o desenvolvimento dos aspectos sociais, linguísticos e comportamentais, além de maior autonomia e segurança na realização dessas atividades.

O estudo aqui descrito focalizou um grupo de crianças com diagnóstico de prematuridade ao nascimento, de baixo nível socioeconômico. A impossibilidade de extensão dos dados aqui relatados para outros sujeitos da mesma população deste estudo, por não obtenção do contato para a convocação, ou pelo não comparecimento no dia da avaliação, configurou-se como uma limitação à pesquisa.

Os resultados aqui relatados estabelecem direções para futuras pesquisas, cujo objetivo seja o de descrever e comparar a complexidade da linguagem em diferentes populações de crianças, o que permitirá ou não confirmar a relação entre o desempenho dos participantes, prematuridade e interação mãe-criança.

\section{CONCLUSÃO}

Os participantes da pesquisa apresentaram desempenho abaixo do esperado para a idade cronológica, para quase todas as provas realizadas. Três fatores, em conjunto ou associados, podem justificar o desempenho dos sujeitos da pesquisa: o fator biológico, como a prematuridade, baixo peso e intercorrências pré-natais, peri-natais ou pós-natais; o fator sociocultural, como grau de instrução, nível socioeconômico, cultura em que a família está inserida e a interação mãe-criança, em que a mãe, sendo o modelo sociolinguístico de seu filho, pode atenuar as consequências das questões acima relatadas, se estabelecer uma interação estimuladora com ele.

\section{REFERÊNCIAS}

1. Custódio S, Cruz O. As representações mentais das crianças acerca das figuras parentais. Psic Teor e Pesq. 2008;24(4):393-405.

2. Dessen MA, Polonia AC. A família e a escola como contextos de desenvolvimento humano. Paidéia. 2007;17(36):21-32.

3. Klein VC, Linhares MBM. Prematuridade e interação mãe-criança: revisão sistemática da literatura. Psicol Estud. 2006;11(2):277-84.

4. Vaz FAC. Prematuridade: fatores etiológicos. Pediatria. 1986;8(3):169-71.

5. Linhares MBM, Carvalho AEV, Machado C, Martinez FE. Desenvolvimento de bebês nascidos pré-termo no primeiro ano de vida. Paidéia. 2003;13(25):59-72.

6. Thomaz ACP, Lima MRT, Tavares CHF, Oliveira CG. Relações afetivas entre mães e recém-nascidos a termo e pré-termo: variáveis sociais e perinatais. Estudos de Psicologia. 2005;10(1):139-46.

7. Araújo BBM, Rodrigues BMRD. Vivências e perspectivas maternas na internação do filho prematuro de Unidade de Tratamento Intensivo Neonatal. Rev Esc Enferm USP. 2010;44(4):865-72.

8. Braga DF, Machado MMT, Bosi MLM. Amamentação exclusiva de recém-nascidos prematuros: percepções e experiências de lactantes usuárias de um serviço público especializado. Rev Nutr. 2008;21(3):293-302.

9. Mello RR, Meio MDBB. Follow-up de recém-nascido de risco. In: Moreira MEL, Braga NA, Morsch DS. Quando a vida começa diferente: o bebê a sua família na UTI neonatal. Rio de Janeiro: Fiocruz; 2003.

10. Perissinoto J. Atuação fonoaudiológica com o bebê prematuro: acompanhamento do desenvolvimento. In: Andrade CRF. Fonoaudiologia em berçário normal e de risco. São Paulo: Lovise; 1996.

11. Moura MLS, Ribas AFP. Desenvolvimento e contexto sociocultural: a gênese da

atividade mediada nas interações iniciais mãe-bebê. Psicol Refl Crít. 2000;13(2):245-56.

12. Foster-Cohen S, Edgin JO, Champion PR, Woodward LJ. Early delayed languagem development in very preterm infants: evidence from the MacArthur-Bates CDI. J Child Lang. 2007;34(3):655-75.

13. Andrade CRF, Befi-Lopes DM, Fernandes FDM, Weetzner HF. ABFW: Teste de linguagem infantil nas áreas de fonologia, vocabulário, fluência e pragmática. Carapicuíba: Pró-Fono; 2000.

14. França M, França E. Tuca, vovó e Guto. São Paulo: Ática; 1987.

15. Spinillo AG, Martins RA. Uma análise da produção de histórias coerentes por crianças. Psicol Refl Crít. 1997;10(2):219-48.

16. Oliveira LN, Lima MCMP, Gonçalves, VMG. Acompanhamento de lactentes com baixo peso ao nascimento: aquisição de linguagem. Arq Neuro Psiquiatr. 2003;61(3-B):802-7.

17. Gomes AL. A relação mãe-bebê na situação de prematuridade extrema: possibilidades de intervenção da equipe multiprofissional. Psicologia Hospitalar. 2004;2(2).

18. Cavalheiro LG, Keske-Soares M. Prevalência do desvio fonológico em crianças de 4 a 6 anos de idade. Pró-Fono. 2008;20(supl):11-3.

19. Papp ACCS, Wertzner HF. O aspecto familial e o transtorno fonológico. Pró-Fono. 2006;18(2):151-60. 
20. Newland LA, Roggman LA, Boyce LK. The development of social toy play and language in infancy. Infant Behav Dev. 2001;24(1):1-25.

21. Mendes DMLF, Moura MLS. Desenvolvimento da brincadeira e linguagem em bebês de 20 meses. Psic Teor e Pesq. 2004;20(3):21522.

22. Neitzel C, Stright AD. Mothers'scaffolding of children's problem solving: establising a fondation of academic self-regulatory competence. J Fam Psychol. 2003;17(1):147-59.

23. Gonçalves F, Borges MGBD. Coerência textual: um estudo com jovens e adultos. Psicol Refl Crít. 2003;16(1):29-40.

24. Naigles L, Hoff E. How children use input to acquire a lexicon. Child Dev. 2002;73(2):418-33.
25. Scopel RR, Souza VC, Lemos SMA. A influência do ambiente familiar e escolar na aquisição e no desenvolvimento da linguagem: revisão de literatura. Rev. CEFAC. 2012;14(4):732-41.

26. Meira I. Abordagem Fenomenológica da Fluência. In: Ferreira LP, Befi-Lopes DM, Limongi SCO. Tratado de Fonoaudiologia. São Paulo: Roca; 2004. p.1017-26.

27. Andrade CRF. Diagnóstico e intervenção precoce no tratamento das gagueiras infantis. Carapicuíba: Pró-Fono; 2004.

28. Caravale B, Tozzi C, Albino G, Vicari S. Cognitive development in low risk preterm infants at three to four years of life. Arch Dis Child. Fetal Neonatal Ed. 2005;90(6):F474-F479.

\section{Anexo 1. Anamnese}

\section{Identificação \\ Nome da criança: \\ Data de Nascimento: \\ Escola:}

Nome do pai:

Data de nascimento:

Naturalidade

Escolaridade:

Trabalho:

Nome da mãe:

Data de nascimento:

Naturalidade

Escolaridade:

Trabalho:

Endereço:

Telefone:

Estrutura da moradia:

Moradores da casa:

Renda familiar:

Centro de Saúde de Referência:

\section{Histórico materno}

a) Estado civil:

b) Número de filhos:

c) Número de abortos:

d) A gravidez foi planejada? Como foi recebida a notícia da gravidez?

E pelo pai?

e) Problemas de saúde/algum outro tipo de problema (além de físico) durante a gestação?

f) Uso de medicamentos/álcool/drogas/tabaco/contato com RX?

g) Algum tipo de deficiência ou dependência química na família? Consanguinidade?

h) Foi internada durante a gestação?

i) Tipo de parto

j) Intercorrências pré-natais

k) Intercorrências pós-natais

I) Já teve outros filhos prematuros?

m) Teve contato com casos de prematuros na família/amigos etc?

\section{Histórico da criança \\ a) Data da internação: \\ b) APGAR \\ c) Peso ao nascimento}

d) Capurro

e) Diagnóstico

f) Intercorrências

g) Medicamentos

h) Cirurgias

i) Tempo de internação

j) Alimentação durante após a internação?

k) Acompanhamento pós-internação? Onde? Quais profissionais?

l) Desenvolvimento motor?

$\mathrm{m})$ Desenvolvimento de fala e linguagem?

n) Faz algum tipo de tratamento?

o) Internações?

\section{Interação materno-infantil}

a) Quando soube que o bebê ia ser prematuro?

b) O que esperava que acontecesse quando soube que seu filho seria prematuro?

c) Recebeu orientações quanto a prematuridade e como seria um bebê prematuro?

d) Como você sentiu durante a internação do bebê?

e) O que você esperava que acontecesse durante a internação.

f) Recebeu orientações durante o período de internação? De quais profissionais?

g) Conversou com outras mães de bebês prematuros?

h) Você observou ou observa alguma diferença do(a) seu/sua filho (a) em relação aos seus outros filhos?

i) Você recebeu orientações a respeito de como é o desenvolvimento de uma criança nascida a termo?

j) Você amamentou seu filho? Quanto tempo?

k) A criança fez ou faz algo diferente do que você esperava?

I) O desenvolvimento motor (rolar, sentar, engatinhar, andar) foi dentro daquilo que você esperava?

m) Quando balbuciou (primeiros sons?)

n) Quando falou as primeiras palavras?

o) Por volta de quantos anos começou a falar mais palavras e produzir frases de 2 palavras?

p) Sempre foi compreendida pelas pessoas?

q) Expressava-se mais através de gestos ou palavras?

r) Quando sorriu? E quando começou a te diferenciar dos outros, "estranhando"?

s) Como você descreveria a criança está hoje? Se não entender: Ela faz alguma coisa diferente do que vc esperava?

t) A criança expressa-se com clareza? É compreendida?

u) Há trocas de sons na fala?

v) A criança conta, inventa histórias, relata fatos ocorridos?

w) Quem é o principal cuidador da criança?

$x)$ A criança fica com outras pessoas? 
y) Como é você acha que é o seu cuidado com relação ao seu/sua filho(a) hoje?

z) Você e o pai da criança participam igualmente dos cuidados com a criança?

\section{Atividades de vida diária e interação materno-infantil}

aa) Você e a criança conversam? Sobre o que conversam?

bb) $\mathrm{O}$ que você faz quando ela/ele decide fazer alguma coisa sem ajuda?

cc) Quanto tempo dispõe para a criança?

dd) Quais são as atividades realizadas com a criança?

ee) Com quem a criança conversa mais?

ff) Quais são os lugares que você costuma levar a criança?

gg) Como você descreveria o jeito de ser de seu/sua filho(a)?

hh) Na gravidez você recebeu mais orientações sobre cuidados com o bebê, estimulação do bebê ou como fazer para ele (a) ser bem comportado (a)?

ii) Quem a orientou quanto a estes aspectos durante a gravidez?

jj) O que é mais importante para você na educação de uma criança: ensinar a seguir regras, ser obediente ou conversar, brincar? Por que? kk) O que você acha que é mais importante para uma criança: saber se comportar, isto é, conviver com a família, escola, ou estar bem desenvolvida para a idade, ter um bom desempenho na escola?

II) Você limita algum tipo de atividade da criança por conta da saúde da mesma?

$\mathrm{mm}$ ) Como é o comportamento de seu filho quando está com você? E com outras pessoas? nn) (Se fica com algum cuidador) O que esta pessoa que cuida da criança valoriza mais? Conversar/brincar, cuidar da higiene/alimentação ou do comportamento da criança?

oo) O fato de você trabalhar faz com que você se dedique mais a uma atividade do que outras quando é você que está cuidando do seu (sua) filho (a)? Se sim, qual destas: cuidado com saúde/higiene/conversas/ brincadeiras ou educação/obediência?

pp) Você observou alguma diferença na sua forma de educar depois que ele/ela nasceu?

qq) O que você faz quando a criança faz algo errado? (Ex. bater, conversar, gritar, castigos, não faz nada).

rr) Desde quando a criança está na escola?

ss) Como é o desempenho escolar da criança?

tt) O que explica o desempenho da criança na escola?

uu) Qual o sentimento da criança com relação à escola?

vv) Qual o relato da escola em relação à criança?

ww) Como é o comportamento da criança na escola? E em casa? Tem amigos?

xx) Quais são as brincadeiras preferidas da criança? Com quem brinca? Aonde? Quanto tempo dispõe para brincar?

yy) A criança gosta de brincar em grupo ou sozinha?

zz) A criança gosta de brincar com crianças mais novas, da mesma idade e/ou mais velhas?

aaa) Vocês brincam com ela? do que? contam histórias? (se sim: quais)

bbb) Ela vê TV? Quanto tempo por dia? o que ela gosta de ver?

ccc) Como ela dorme? A que horas dorme? Com quem dorme? 